Article

\title{
Regioselective Synthesis of Lactulose Esters by Candida antarctica and Thermomyces lanuginosus Lipases
}

\author{
Luis F. Chávez-Flores ${ }^{1}$, Hiram Isaac Beltran ${ }^{2}$, Daniel Arrieta-Baez ${ }^{3}$ and Dolores Reyes-Duarte ${ }^{4, *}$ \\ 1 Posgrado en Ciencias Naturales e Ingeniería, Universidad Autónoma Metropolitana-Unidad Cuajimalpa, \\ Av. Vasco de Quiroga 4871, Col. Santa Fe Cuajimalpa, Deleg. Cuajimalpa de Morelos 05348 CDMX, Mexico; \\ 2122800606@alumnos.cua.uam.mx \\ 2 Departamento de Ciencias Naturales, Universidad Autónoma Metropolitana-Unidad Cuajimalpa, \\ Av. Vasco de Quiroga 4871, Col. Santa Fe Cuajimalpa, Deleg. Cuajimalpa de Morelos 05348 CDMX, Mexico; \\ hbeltran@correo.cua.uam.mx \\ 3 Instituto Politécnico Nacional - CNMN, Calle Luis Enrique Erro s/n, Unidad Profesional Adolfo López \\ Mateos, Col. Zacatenco, México D.F. CP 07738, Mexico; darrieta@ipn.mx \\ 4 Departamento de Procesos y Tecnología, Universidad Autónoma Metropolitana-Unidad Cuajimalpa, \\ Av. Vasco de Quiroga 4871, Col. Santa Fe Cuajimalpa, Deleg. Cuajimalpa de Morelos 05348 CDMX, Mexico \\ * Correspondence: dreyes@correo.cua.uam.mx; Tel.: +52-55-581-465-00 (ext. 3872)
}

Received: 14 August 2017; Accepted: 29 August 2017; Published: 3 September 2017

\begin{abstract}
The interest in sugar esters as emulsifiers has been increasing in recent years because they have tunable surfactant properties that depend on the chain length of the fatty acid and the type of the sugar, covering a wide range of hydrophilic-lipophilic balance (HLB). In this work, ten biocatalysts were used for the transesterification reaction screening of lactulose, a prebiotic sugar, with vinyl laurate. The reactions were followed by thin layer chromatography (TLC) analysis, identifying two major monoesters mixtures defined as monoester fraction 1 and monoester fraction 2. Candida antarctica lipase B (Novozym 435) produces "monoester fraction 1", while Thermomyces lanuginosus lipase (Lipozyme ${ }^{\circledR}$ TL IM) and Mucor miehei lipase (Lipozyme ${ }^{\circledR}$ ) seem to produce the same "monoester fraction 2". These three enzymes were selected as model biocatalysts for a kinetic study, and monoester fractions 1 and 2 from Novozym 435 and Lipozyme ${ }^{\circledR}$ TL IM, respectively, were used for product characterization. Monoester fraction 1 contained $86.9 \%$ of the major monoester in position 1-O-, and monoester fraction 2 contained $91.4 \%$ of $6^{\prime}-O-$. Although these lipases acylated three positions of lactulose, they mainly synthesize a monoester presenting regioselectivity. These results contribute to the study of the chemical structure diversity of biosurfactants to enhance their applications in foods, pharmaceutical products, and cosmetics.
\end{abstract}

Keywords: biocatalysts; lipases; lactulose; prebiotic sugar; sugar fatty acid esters; transesterification; regioselectivity

\section{Introduction}

Sugar fatty acid esters have a wide range of applications in the food, cosmetic, detergent, and pharmaceutical industries [1]. They present interesting properties as surfactant [2], antimicrobial [3-8], antitumoral [9], and insecticide agents [10]. The degree of esterification and the type of fatty acid used determine their surfactant properties. It has also been demonstrated that sucrose esters (mono-, di-, or tri-esters) are hydrolysed to sucrose and fatty acids prior to intestinal absorption [11,12], giving them a GRAS (Generally Recognized As Safe) status [13]. Although different sugars and acyl donors have been widely studied $[1,6,14-17]$, the use of a single sugar with prebiotic properties, such as 
lactulose, has been less studied [18,19] and might open significant applications in the food and pharmaceutical fields.

Lactulose is the simplest existent prebiotic. It is a disaccharide composed of galactose and fructose (4-O- $\beta$-D-galactopyranosyl-D-fructofuranose), and, in contrast to lactose, cannot be hydrolyzed due to its resistance to digestive enzymes, and therefore reaches the colon without alteration. There, lactulose is selectively metabolized by bifidobacterias and lactobacillus to lactic and acetic acids, reducing intestinal $\mathrm{pH}$. These actions improve the gastrointestinal environment and microbiota presence and help to avoid the occurrence of constipation [20]. Therefore, lactulose is extensively used in infant and senior nutrition as a prebiotic [21].

On the other hand, lipases' regioselectivity has been explored and used as an advantage for enzymatic synthesis over chemical synthesis. Nevertheless, due to the abundance of different hydroxyl groups in sugars, it is necessary to evaluate the behavior of enzymes to achieve a "directed enzymatic synthesis" for selective sugar esters. Enzymatic esterification using fructose, galactose-sugars that form lactulose-, lactose, and sucrose have been previously reported. Figure 1 shows the acylation positions of these sugars according to the following tendency: (a) fructose: 6-O- [22-26], 1-O- [23,27], and 1,6-O- [26]; (b) galactose: 6-O- [23,28,29]; (c) sucrose: $1^{\prime}-O-$ [30-32], 6-O- [33-37], 6'-O- [33-35], 6,1-O-, and 6,6'-O- [37]; (d) lactose: 6'-O- [34]; (e) lactulose: 1-O- [30]. Other studies on the synthesis of lactulose esters have been previously reported; however, to the best of our knowledge, the acylation position has not been described $[18,19]$.

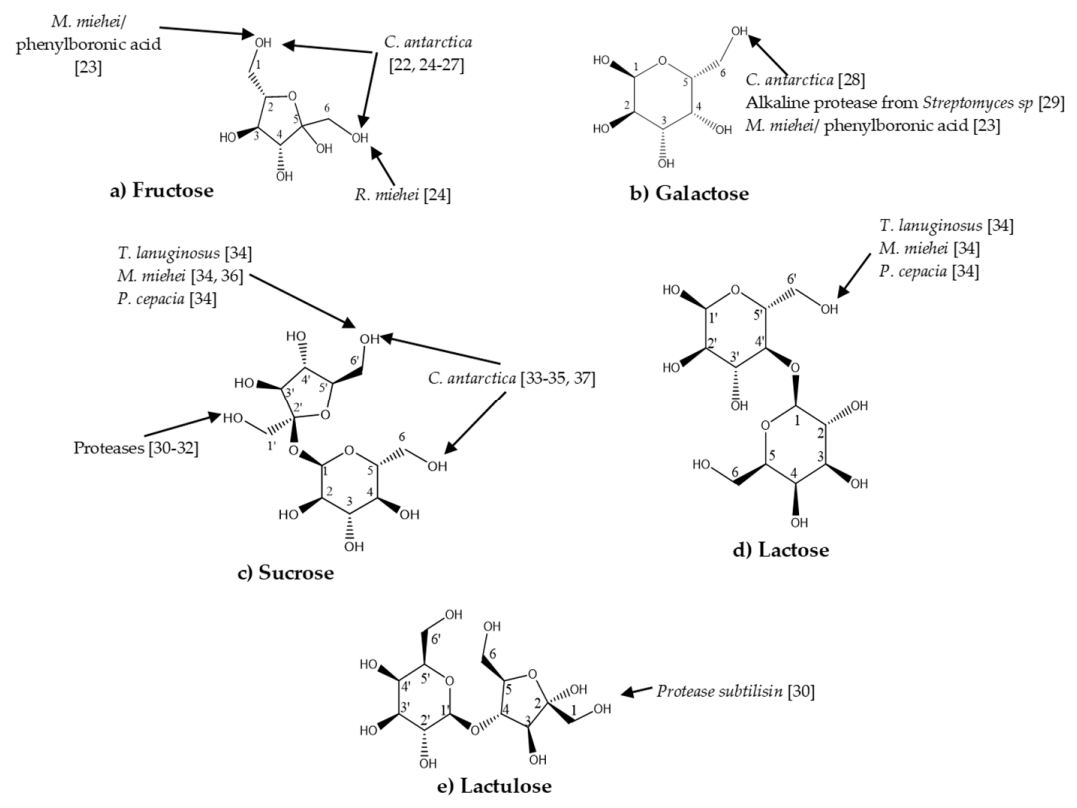

Figure 1. Acylation positions of several sugars with different biocatalysts.

In this work, we study the regioselective synthesis of lactulose esters, controlling the esterification position into the lactulose molecule as well as the esterification degree through modulating the biocatalyst used and the solvent composition in order to modify the structures of the lactulose esters and their properties.

\section{Results}

\subsection{Enzymatic Synthesis of Lactulose Esters and Screening with Different Biocatalysts}

The synthesis of lactulose esters was developed by transesterification with vinyl laurate, an acyl donor that shifts the equilibrium reaction towards ester formation due to a well-known vinyl alcohol 
tautomerization to acetaldehyde and product evaporation [37]. The enzymatic model reaction is shown in Figure 2.

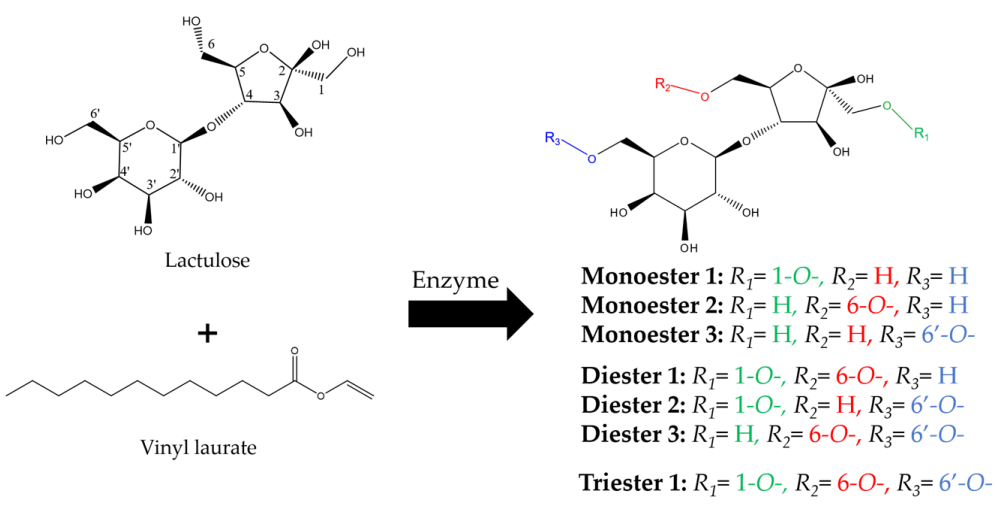

Figure 2. Studied enzymatic reactions. $R_{1}, R_{2}$, and $R_{3}$ are the acylation positions in lactulose, where each $\mathrm{R}$ is a lauryl residue. When the synthesis of monoesters occurs, the acylation positions are 1-O-, 6-O-, or 6'-O-, diester: (1-O-, 6-O-), (1-O-, 6'-O-), or (6-O-, 6'-O-), and triester: (1-O-, 6-O-, 6'-O-).

Ten biocatalysts were used for the transesterification reaction screening, and they are shown in Figure 3a,b. Candida antarctica lipase B immobilized in acrylic resin (Novozym 435), Mucor miehei lipase immobilized on a macroporus ion-exchange resin (Lipozyme ${ }^{\circledR}$ ), Thermomyces lanuginosus lipase immobilized as silica granulated (Lipozyme ${ }^{\circledR}$ TL IM), and Alcaligenes sp. lipase immobilized in granulated diatomaceous earth (QLG) showed activity and different products were observed. The monoesters produced with Lipozyme TL IM, Lipozyme, and QLG have the same retention factor $\left(R_{f}=0.289\right)$, while with Novozym 435 the $R_{f}$ is 0.235 .

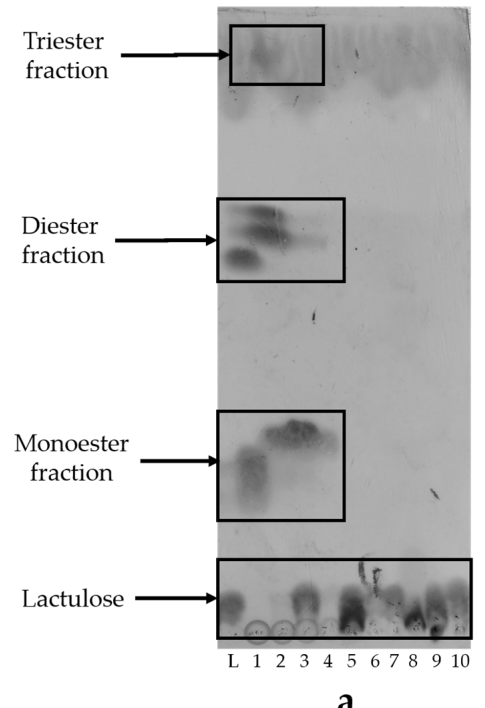

a

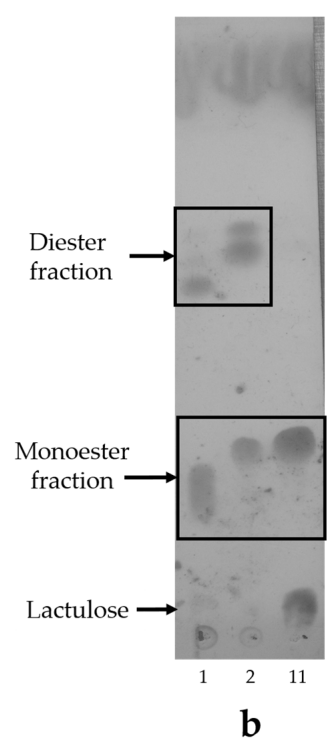

Figure 3. Product profile of the enzyme screening developed in thin layer chromatography (TLC) plates. Reaction conditions: biocatalyst $(25 \mathrm{mg} / \mathrm{mL})$, lactulose $(30 \mathrm{mM})$, vinyl laurate $(150 \mathrm{mM}), \mathrm{T}=60{ }^{\circ} \mathrm{C}$, $t=24 \mathrm{~h}$, solvent: 20\% DMF in 2-methyl-2-butanol (2M-2B). (a) Lines: (L) Lactulose, (1) Novozym 435, (2) Lipozyme TL IM, (3) Lipozyme from Mucor miehei 20\% DMF, (4) Lipozyme from Mucor miehei 0\% DMF, (5) Lipase from Rhizopus orizae (Lewatit 160), (6) Lipase from Rhizopus oryzae (LewROL-PEI), (7) Lipase Amano PS from Burkholderia cepacia, (8) Lipase from Rhizomucor miehei (Palatase ${ }^{\circledR} 20,000 \mathrm{~L}$ ), (9) Lipase from porcine pancreas, (10) Protease from Bacillus licheniformis. (b) Lines: (1) Novozym 435, (2) Lipozyme TL IM, (11) Alcaligenes sp. lipase (QLG). 
Three biocatalysts were tested by their ability to synthesize lactulose esters. After one hour, the reaction products were followed by TLC (Figure 4). As observed here, there are two major groups of monoesters, defined as monoester fraction 1 and monoester fraction 2 . The Novozym 435 biocatalyst produces "monoester fraction 1", while Lipozyme TL IM and Lipozyme from Mucor miehei lipases seem to produce the same "monoester fraction 2". These three enzymes were selected as model biocatalysts for the kinetic study, and monoester fractions 1 and 2 from the Novozym 435 and Lipozyme TL IM lipases were used for product characterization.

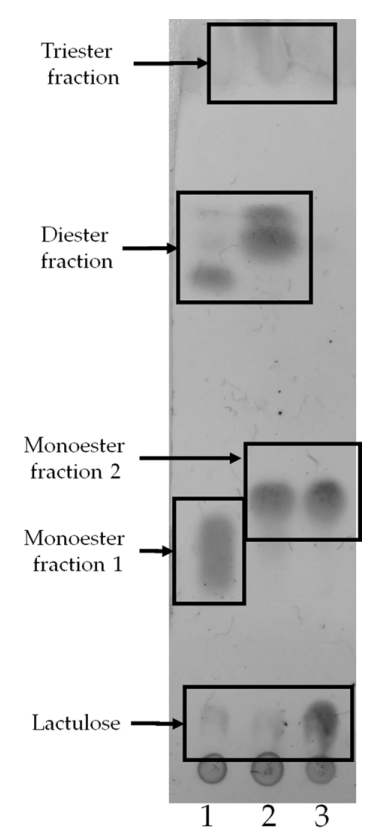

Figure 4. TLC analysis for products profile in a one-hour reaction, using vinyl laurate as acyl donor (150 mM) and lactulose (30 mM) in organic solvent. Lines: (1) Novozym 435, (2) Lipozyme TL IM, and (3) Lipozyme from Mucor miehei.

The monoester fractions obtained were purified by liquid-liquid extraction and flash chromatography, and were characterized by ${ }^{1} \mathrm{H},{ }^{13} \mathrm{C}$, and two-dimensional (2D) (HMBC) NMR, MS-ESI, and FT-IR.

\subsection{Characterization by FT-IR, ${ }^{1} H,{ }^{13} \mathrm{C}$, and $2 D$ (HMBC) NMR and MS-ESI}

FT-IR: The analysis of the FT-IR data has shown a specific band at $1740 \mathrm{~cm}^{-1}$, clearly stating the presence of $\mathrm{C}=\mathrm{O}$ ester stretching vibrations.

Electrospray Mass Spectrometry (MS-ESI) Analysis: The products' reaction was first analyzed by MS-ESI (+). Electrospray is a technique where droplets are generated when a high voltage is applied to a liquid stream. In the ESI process, a population of variably charged ions is generated. In this study, the monoesters' spectra mainly contain $[\mathrm{M}+\mathrm{H}]^{+},[\mathrm{M}+\mathrm{Na}]^{+}$, or $[\mathrm{M}+\mathrm{K}]^{+}$.

Both mixture reactions were injected separately in a direct form into the spectrometer to analyze the products formed. According to the ESI (+) mass spectra, both enzymes produce a monoester with an $m / z$ of 547.2738 (For a $\left[\mathrm{C}_{24} \mathrm{H}_{44} \mathrm{O}_{12}+\mathrm{Na}\right]+$ calc., $m / z$ 547.2730). However, when enzyme Lipozyme TL IM was used instead of Novozym 435, the reaction products were purer (Figure 5). 


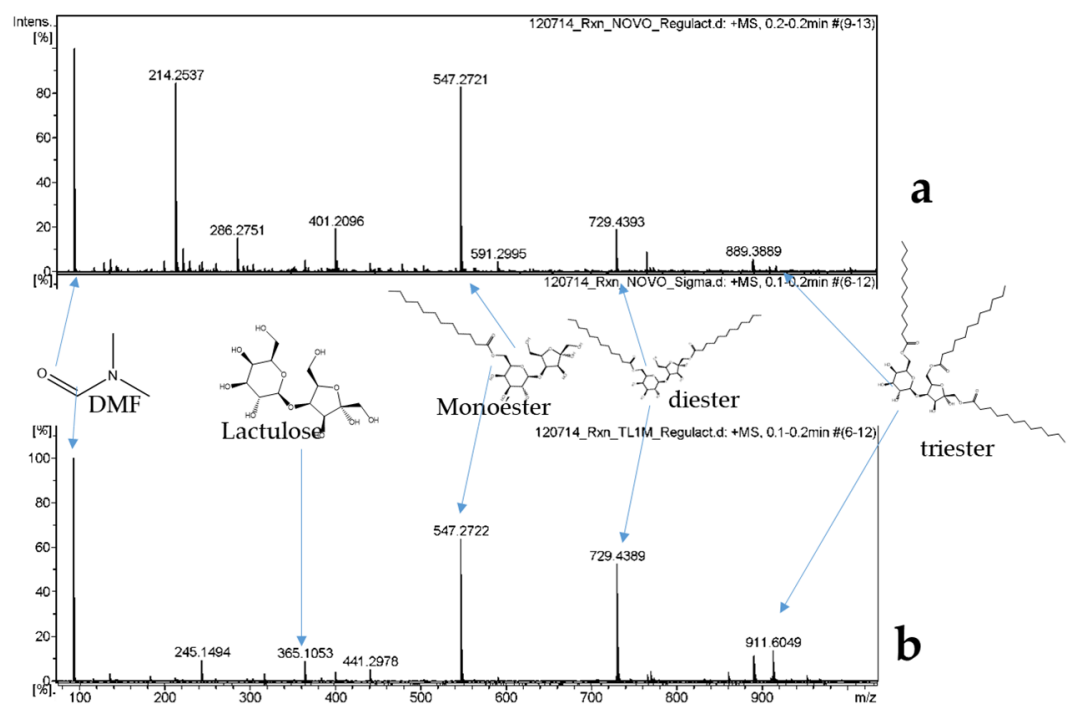

Figure 5. ESI graphs of the complete reaction of: (a) Novozym 435; (b) Lipozyme TL IM.

The signals observed in the products from Lipozyme TL IM belong to the monoester fragmentation, as we can see in Figure 6b, and this fragmentation was not observed when products from Novozym 435 were analyzed (Figure 6a), indicating that it is not the same product.

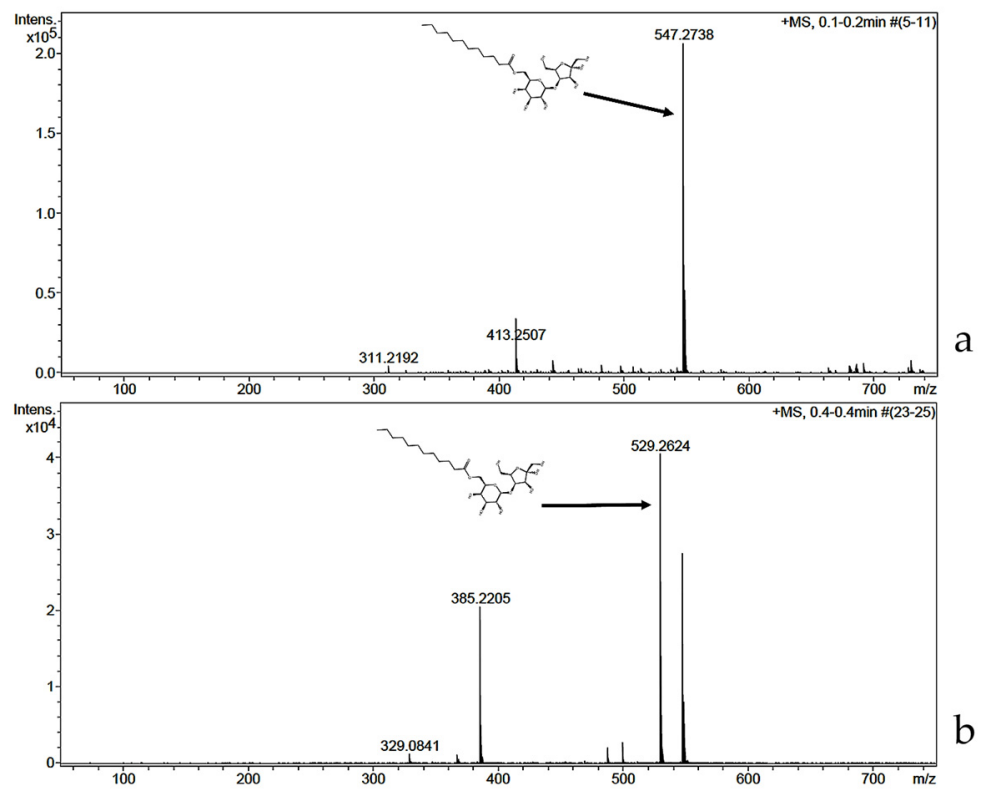

Figure 6. MS-ESI (+) spectra from the purified reaction products: (a) Monoester fraction 1 of Novozym 435; (b) Monoester fraction 2 of Lipozyme TL IM.

NMR Analysis: The ${ }^{1} \mathrm{H}-\mathrm{NMR}$ spectrum of the monoester fractions from the lipase-catalyzed reactions clearly shows a group of signals that belong to more than one product, which means that there are at least two different acylation positions in monoesters (Table 1). 
Table 1. Comparative NMR data of the experimental and predicted data of monoesters 1,6 , and $6^{\prime}$.

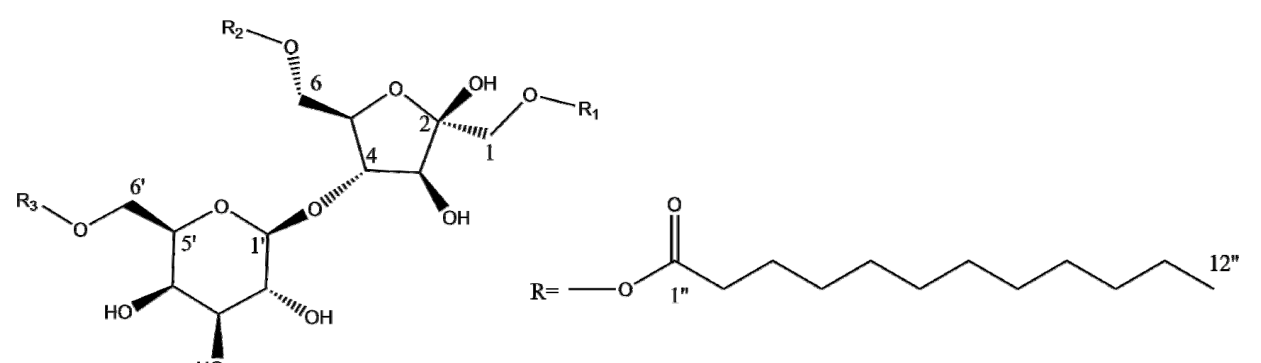

Monoester 1-O-: $R_{2}, R_{3}=\mathrm{H}$

Monoester 6-O-: $R_{1}, R_{2}=\mathrm{H}$

Monoester 6-O-: $R_{1}, R_{3}=\mathrm{H}$

\begin{tabular}{|c|c|c|c|c|c|c|c|c|c|c|c|}
\hline \multirow{2}{*}{$\begin{array}{l}\text { Monoester } \\
\text { Fraction }\end{array}$} & \multicolumn{5}{|c|}{$\begin{array}{c}\text { Monoester-1 (1-O) } \\
\text { (ppm) }\end{array}$} & \multicolumn{4}{|c|}{$\begin{array}{c}\text { Monoester-6 (6-O) } \\
(\mathrm{ppm})\end{array}$} & \multicolumn{2}{|c|}{$\begin{array}{c}\text { Monoester- } 6^{\prime}\left(6^{\prime}-O\right) \\
(\mathrm{ppm})\end{array}$} \\
\hline & Atom & ${ }^{13} C_{\exp }$ & ${ }^{13} C_{\text {cal }}$ & ${ }^{1} \mathbf{H}_{\text {exp }}$ & ${ }^{1} \mathbf{H}_{\mathrm{cal}}$ & ${ }^{13} C_{\text {exp }}$ & ${ }^{13} C_{\text {cal }}$ & ${ }^{1} \mathbf{H}_{\exp }$ & ${ }^{1} \mathbf{H}_{\mathrm{cal}}$ & ${ }^{13} C_{\text {exp }}$ & ${ }^{13} C_{\text {cal }}$ \\
\hline \multirow{3}{*}{$\begin{array}{c}\text { Fructose } \\
\text { moiety }\end{array}$} & 2 & 103.11 & 103.01 & & & 104.62 & 104.43 & & & 104.12 & 104.43 \\
\hline & 4 & 87.00 & 87.18 & $3.61(\mathrm{dd})$ & $3.65(\mathrm{dd})$ & 87.01 & 87.18 & $3.60(\mathrm{dd})$ & $3.63(\mathrm{dd})$ & 86.9 & 88.20 \\
\hline & 6 & 63.79 & 63.81 & $4.00,3.58$ & $3.99,3.58$ & 63.80 & 63.81 & 4.45 & $4.32,4.07$ & - & - \\
\hline \multirow{2}{*}{$\begin{array}{l}\text { Galactose } \\
\text { moiety }\end{array}$} & $5^{\prime}$ & 76.08 & 76.69 & & & 74.96 & 74.94 & & & & \\
\hline & $6^{\prime}$ & 61.43 & 61.72 & $3.70,3.46$ & $3.70,3.50$ & 62.63 & 62.56 & $4.14(\mathrm{dd})$ & $4.13(\mathrm{dd})$ & 4.42 & 4.324 .07 \\
\hline \multirow{2}{*}{$\begin{array}{l}\text { Lauroyl } \\
\text { moiety }\end{array}$} & $1^{\prime \prime}$ & 173.5 & 173.5 & & & 174.1 & 174.1 & & & 173.8 & 173.5 \\
\hline & $2^{\prime \prime}$ & 33.58 & 34.03 & $2.38(\mathrm{~m})$ & $2.34(\mathrm{~m})$ & 33.56 & 34.03 & 2.39 & $2.37(\mathrm{~m})$ & & \\
\hline
\end{tabular}

According to the ${ }^{13} \mathrm{C}$ NMR analysis, three different lactulose monoesters could be identified. When the acylation occurs in position 1 of the fructose moiety (Monoester-1 (1-O-), Table 1) the chemical shift of the C-1 was found at $64.0 \mathrm{ppm}$, whereas if the acylation is located in position C- $6^{\prime}$ of the galactose moiety the signal is located at $\delta 62.63 \mathrm{ppm}$ (Monoester- $6^{\prime}\left(6^{\prime}-O-\right)$, Table 1$)$. These observations corroborated with the predicted carbonyl signals of the monoesters at the ${ }^{13} \mathrm{C} N \mathrm{NMR}$. Two carbonyl signals were observed at $\delta 173.5 \mathrm{ppm}$ for the acylation in position C-1 of the fructose, and another signal at $\delta 174.1 \mathrm{ppm}$ for the acylation in position C- $6^{\prime}$ of the galactose. The NMR analysis of the fractions showed two signals that could indicate the presence of another monoester. Signals at $\delta 64.21$ and $173.8 \mathrm{ppm}$ belong to another structure, probably to a monoester with acylation in position C-6 of the fructose moiety (Monoester-6 (6-O-), Table 1). This signal showed correlation in $\mathrm{HMBC}$ indicating the presence of this monoester. The ${ }^{1} \mathrm{H}$ and ${ }^{13} \mathrm{C}$ NMR spectra can be viewed in Supplementary Figures S1a,b and S2a,b.

Signals assignments where corroborated with the HMBC 2D NMR spectral analysis of the products by the correlation of the carbonyl signals with the C-2" of the lauroyl chain (Figure S3a,b).

According to the observations in the ${ }^{13} \mathrm{C}$ NMR spectrum (Figure S2a), three products (Table 1) were found in the Novozyme 435-catalyzed reaction. However, only two monoesters (1-O- and $\left.6^{\prime}-\mathrm{O}-\right)$ were identified when Lipozyme TL IM was used to catalyze the reaction (Figure S2b) (Table 1). This could be explained from the point of view of the steric hindrance to achieve ester formation. As we could see in Figure 7,- $-\mathrm{OH}$ in position $6^{\prime}$ of the galactose moiety are more sterically available instead of $\mathrm{C}-\mathrm{OH}$ in position 6 of the fructose moiety. Therefore, this means that the lipase Lipozyme TL IM is more selective to produce only two isomers of the monoester, while the lipase Novozym 435 does not have this restriction to produce more isomers, as it was demonstrated with this analysis. 


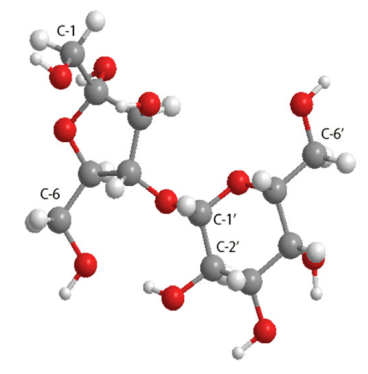

Figure 7. Structural conformation of the lactulose, evidencing the less steric-hindered C-1 and C- $6^{\prime}$ C-OH positions.

The proportion of monoesters synthesized by lipases from Novozym 435 and Lipozyme TL IM was determined by a ${ }^{1} \mathrm{H}$ NMR signal integration of the characteristic chemical shifts at each monoester, where the characteristic chemical shifts of each molecule were identified. This was also performed in order to aid in the quantification of each molecule, and this was feasible because each molecule presented a characteristic chemical shift without overlap among at least one of their signals and thus were differentiable to determine proportions through signal integration.

As stated, the ${ }^{1} \mathrm{H}$ NMR signals corresponding to each monoester were integrated to identify and quantify the studied molecules, and each one appeared as a doublet with displacements of 4.39 (Monoester-1 (1-O)), 4.42 (Monoester-6' (6'-O)), and 4.45 (Monoester-6 (6-O)) ppm from Novozym 435 (Figure S4) and from Lipozyme TL IM at 4.39 (Monoester-1 (1-O)) and 4.42 (Monoester- $6^{\prime}\left(6^{\prime}-O\right)$ ) ppm (Figure S5).

The signals from each monoester contained in the mixture generated by Novozym 435 were identified and integrated: a doublet to $-\mathrm{H}$ of C-1 4.39 ppm and integration of 1, - $\mathrm{H}$ of C-6 $4.42 \mathrm{ppm}$ and integration of 0.1 , and $-\mathrm{H}$ of $\mathrm{C}-6$ at $4.45 \mathrm{ppm}$ and integration of 0.05 . The integration of the proton related to $C-1^{\prime}$ appearing as a doublet at $3.92 \mathrm{ppm}$ resulted in 1.15 (Figure S4), coinciding with the sum of the integrals of the three doublets described above, and also indicating that no other isomers or related structures were present. The mixture contained $87 \%$ of $1-\mathrm{O}-$, which is the major monoester, $8.7 \%$ of $6-\mathrm{O}-$, and $4.3 \%$ of $6^{\prime}-\mathrm{O}-$.

The signals in the ${ }^{1} \mathrm{H}$ spectra resulting from the Lipozyme TL IM catalyzed-synthesis were identified: $3.92 \mathrm{ppm}, 3.93 \mathrm{ppm}$, and integration of 1.09 for the doublet proton related to C-1', $-\mathrm{H}$ of $\mathrm{C}-1$ at $4.39 \mathrm{ppm}$ and integration of 0.093 , and $-\mathrm{H}$ of C- $6^{\prime}$ at $4.42 \mathrm{ppm}$ and integration of 1 (Figure S5). The mixture contained $91.5 \%$ of the major monoester ( $\left.6^{\prime}-\mathrm{O}-\right)$ and $8.5 \%$ of the minor one (1-O-). Although lipases from Novozym 435 and Lipozyme TL IM are able to acylate in different positions of lactulose, these mainly synthesized one monoester, presenting regioselectivity. Comparing the lipase acylation positions for disaccharides reported in the literature (Figure 1c,d), the produced monoesters also gathered the acyl moiety in the two less steric-hindered 1-O-and $6^{\prime}-O$-positions of lactulose, while the 6-O-position remained almost untouched, as occurred in the $1^{\prime}-O$ - of sucrose. In this work, lipase $\mathrm{B}$ from Candida antarctica acylates the less steric-hindered position 1-O- with a yield of $86.9 \%$. On the other hand, Thermomyces lanuginosus lipase prefers the acylation of lactose (Figure $1 \mathrm{~d}$ ) in position $6^{\prime}$-O(in galactose), coinciding with this work where Lipozyme TL IM acyls the same position of lactulose $\left(6^{\prime}-\mathrm{O}^{-}\right)$with a yield of $91.4 \%$.

\subsection{Conversion to Monoester by Selected Enzymes and Effect of Temperature in the Reaction}

Figure 8 shows the time-course of the mixture of monoesters produced by each catalyzed reaction at 30 and $60{ }^{\circ} \mathrm{C}$, observed as one monoester peak in a HPLC analysis. At $60{ }^{\circ} \mathrm{C}$, Novozyme 435 and Lipozyme TL IM had similar behaviour: maximum monoesters production in short time $(21.6 \mathrm{~mm}$ of monoesters in $1.5 \mathrm{~h}$ and $12.3 \mathrm{~mm}$ in $1 \mathrm{~h}$, respectively). The decay in the concentration was due to the formation of diesters and triesters, observed by HPLC analysis (data not shown). Lipozyme from Mucor miehei achieved $21.6 \mathrm{~mm}$ in $5 \mathrm{~h}$, with less conversion to diesters. 


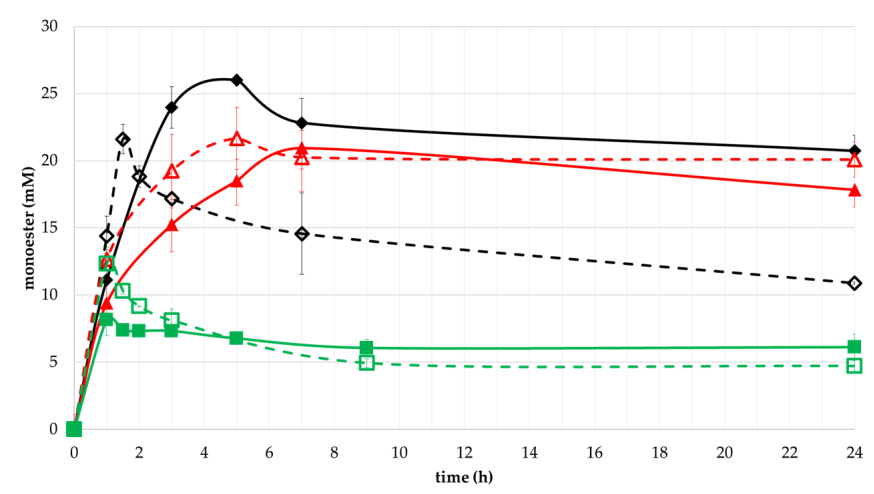

Figure 8. Time-course of the monoester synthesis of lactulose by selected enzymes and effect of temperature in monoester production. Reaction conditions: $30 \mathrm{mM}$ lactulose and $150 \mathrm{mM}$ vinyl laurate, $25 \mathrm{mg} / \mathrm{mL}$ of biocatalyst, 2M2B (20\% DMF). $-\backslash$ Novozym $435,30{ }^{\circ} \mathrm{C}$ and $--\diamond-60{ }^{\circ} \mathrm{C}$; $-\mathbf{\Delta}-$ Lipozyme from Mucor miehei, $30{ }^{\circ} \mathrm{C}$ and - $-\triangle--60{ }^{\circ} \mathrm{C}$, — — Lipozyme TL IM, $30^{\circ} \mathrm{C}$ and - - $\square--60^{\circ} \mathrm{C}$.

When the reaction temperature decreased from 60 to $30{ }^{\circ} \mathrm{C}$, the synthesis of monoesters was preferred over diesters synthesis, and the effect could be translated into an increase in selectivity with a lower temperature. This effect could be observed with Novozyme 435 and Lipozyme TL IM but not with the Lipozyme from the Mucor miehei lipase. In the last case, when the temperature decreased, the synthesis of lactulose monoesters was maintained almost equal from $21.6 \mathrm{~mm}$ in $5 \mathrm{~h}$ to $20.9 \mathrm{~mm}$ in $7 \mathrm{~h}$, and a lower diester production was also observed, possibly due to the active site structure of this type of lipase [38,39], as commented on in the next section.

\section{Effect of Substrates Concentrations on Monoesters Yield}

In order to evaluate the effect of the molar ratio sugar/acyl donor on the transesterification reaction, two conditions were evaluated (Figure 9). A ratio of 1:5 was better than 1:1 for achieving higher yields: Novozym $73 \%$ vs. $6 \%$ in 1.5 h; Lipozyme TL IM $43 \%$ vs. $23 \%$ in 1 h; Lipozyme from Mucor miehei $73 \%$ vs. $37 \%$ in $5 \mathrm{~h}$. Two factors could be involved in this behaviour: (a) due to the lower concentration of acyl donor in the 1:1 reaction, the low water content present was enough for the vinyl laurate's hydrolysis, and therefore the transesterification reaction to sugar esters decreased [40]; (b) the lactulose monoesters produced, due to their amphiphilic behaviour, could help to avoid sugar precipitation, stabilizing the reaction mixture and displacing the equilibrium of the reaction towards transesterification [41,42].

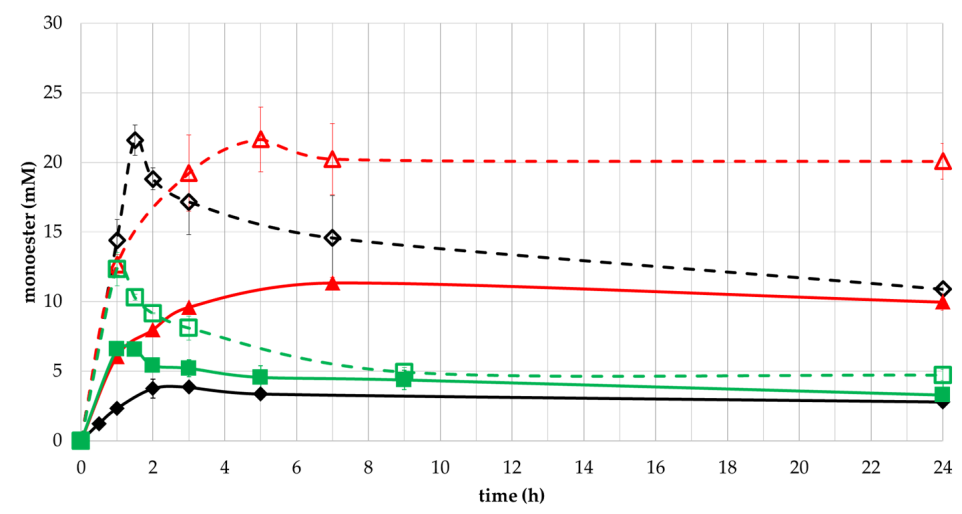

Figure 9. Effect of sugar/acyl donor molar ratio on lactulose monoester enzymatic synthesis in $2 \mathrm{M}-2 \mathrm{~B}$ with 20\% DMF. Reaction conditions: lactulose (30 mM) and vinyl laurate (30 or $150 \mathrm{mM}), 25 \mathrm{mg} / \mathrm{mL}$ of biocatalyst. - -Novozym 435, 1:1 and -- $\checkmark--1: 5$; - - - Lipozyme from Mucor miehei, 1:1 and - - $\triangle$ - - 1:5, ———Lipozyme TL IM, 1:1 and - - $\square-$ - 1:5. 


\subsection{Calculation of the Hydrophilic-Lipophilic Balance (HLB)}

The HLB of an emulsifier is an expression of its Hydrophile-Lipophile Balance, i.e., the balance of the size and strength of the hydrophilic (or polar) and the lipophilic (or nonpolar) groups of the emulsifier. All emulsifiers consist of a molecule that combines both hydrophilic and lipophilic groups [43].

The classification of surfactants by HLB numbers allows for the making of certain predictions of the behaviour of these compounds, facilitating the optimum selection of emulsifiers, wetting agents, and other types of agents, and making a connection between theory and practical applications [44].

\subsubsection{Griffin Method}

$$
\begin{aligned}
& M_{h}=341.29 \mathrm{~g} / \mathrm{mol} \\
& M_{T-\text { mono }}=524.60 \mathrm{~g} / \mathrm{mol} \\
& M_{\text {T-di }}=706.91 \mathrm{~g} / \mathrm{mol} \\
& M_{\text {T-tri }}=889.22 \mathrm{~g} / \mathrm{mol} \\
& H L B_{\text {mono }}=20(341.29 / 524.60)=13.01 \approx 13 \\
& H L B_{d i}=20(341.29 / 706.91)=9.65 \approx 10 \\
& H L B_{\text {tri }}=20(341.29 / 889.22)=7.67 \approx 8
\end{aligned}
$$

where: $H L B_{\text {mono }}$ : HLB value by monoester

$H L B_{d i}:$ HLB value by diester

$H L B_{\text {tri }}:$ HLB value by triester

\subsubsection{Davies Method}

$$
\begin{aligned}
& H L B=\sum n(\text { \#group }-\mathrm{O}-\mathrm{C}=\mathrm{O})+n(\text { \#group }-\mathrm{O}-)+n(\text { \#group }-\mathrm{OH}) \\
& -n \text { (\#group }-\mathrm{CH}-,-\mathrm{CH}_{2}-,-\mathrm{CH}_{3},-\mathrm{C}-\text { ) }+7 \\
& H L B_{\text {mono }}=\sum(2.4)+3(1.3)+7(1.9)-23(0.475)+7=15.675 \approx 16 \\
& H L B_{d i}=\sum 2(2.4)+3(1.3)+6(1.9)-34(0.475)+7=10.95 \approx 11 \\
& H L B_{\text {tri }}=\sum 3(2.4)+3(1.3)+5(1.9)-45(0.475)+7=6.225 \approx 6
\end{aligned}
$$

HLB scale goes from 1 to 20 , where 1 is the most hydrophobic and 20 the most hydrophilic compound. The HLB values from the sucrose and lactulose esters are similar because of their chemical structures. According to their values, these sugar monoesters (Griffin 13 and Davies 16) could be used for dairy drinks, ice creams, or in the production of wheat products and detergents; the diesters (Griffin 10 and Davies 11) in the manufacture of chewing gum and wheat products; and the triesters (Griffin 8 and Davies 6) for processing milk powder and confectionery [2,45].

\section{Discussion}

Novozym 435 recognizes three acylation positions for lactulose monoesters $(8.6 \%$ of $6-O-$ and $4.5 \%$ of $\left.6^{\prime}-\mathrm{O}-\right)$ but shows preferred regioselectivity for $1-O-(86.9 \%)$, whereas Lipozyme TL IM shows regioselectivity for the less steric-hindered 1-O- (8.5\%) and $6^{\prime}-O-(91.4 \%)$ positions of lactulose (Figure 10). 


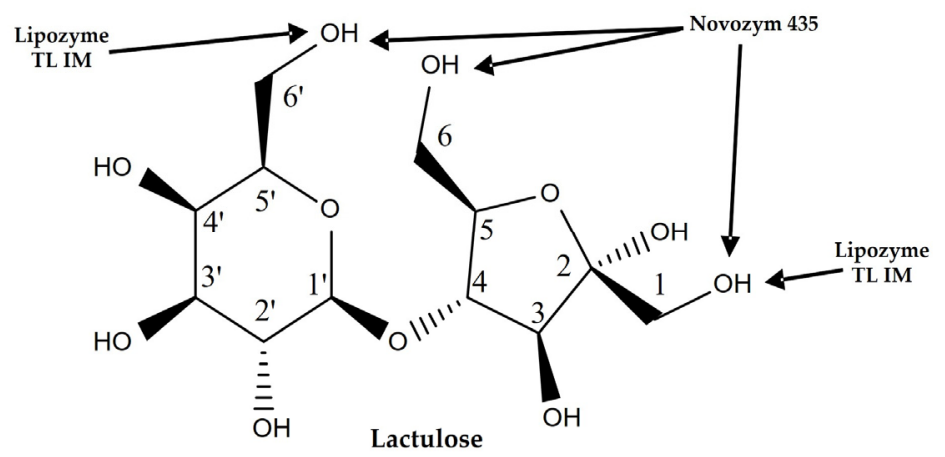

Figure 10. Lactulose acylation positions with Novozym 435 and Lipozyme TL IM.

The difference of this preference could be based on the structural and physicochemical properties of the active sites of these enzymes; whereas Thermomyces lanuginosus lipase (Lipozyme TL IM) has a large cleavage for attachment to alcohols and a narrow cleavage for acyl bonding, the lipase B of Candida antarctica (Novozym 435) has a large cleavage for attachment to the acyl and a small cleavage for attachment to alcohols [46]. This allows Candida antarctica lipase B to accept a wide type of large substrates, while Thermomyces lanuginosus has steric restrictions in its active site, only catalyzing on the most exposed acyl positions. These results match with the already known sn-1(3) specificity of the Thermomyces lanuginosus and Mucor miehei lipases and the non-regiospecificity of Candida antarctica lipase B over triglycerides [38,39]. This work supports the view that lactulose monoesters can be produced while controlling the molecular properties of each enzyme, and that the structure of the substrates and the parameters of the reaction affect the binding enzyme substrate [41]. As shown in this work and coinciding with previous studies, the use of a polar co-solvent ( $20 \% \mathrm{DMF})$ allows the reactions to produce more monoesters due to the improvement of the solubility of the sugar, producing the monoester as the main product [40].

On the other hand, Novozym 435 (reaction conditions: $30^{\circ} \mathrm{C}$ and ratio sugar/acyl donor 1:5) is the best enzyme for the regioselective synthesis of the monoester 1-O-and Lipozyme TL IM for the monoester $6^{\prime}-\mathrm{O}$ - (reaction conditions: $60^{\circ} \mathrm{C}$ and ratio sugar/acyl donor 1:5). Lipozyme from Mucor miehei presumably catalyzed the synthesis of the same monoesters as Lipozyme TL IM; in such a case, it would give higher yields than the last one for producing $6^{\prime}$-O-lactulose monoester (reaction conditions: $60^{\circ} \mathrm{C}$ and ratio sugar/acyl donor 1:5). This work gives us the opportunity to produce new compounds with potential functional properties that have to be explored.

\section{Materials and Methods}

\subsection{Materials}

Lipozyme TL IM ${ }^{\circledR}$ and Novozym $435^{\circledR}$ were kindly donated from Novo Nordisk (Mexico City, Mexico); QLG (from Alcaligenes sp. from Meito Sangyo Co.( Tokyo, Japan)) was donated by F. Plou; and LEW-ROL-PEI and LEW-ROL-160 from Rhyzomucor oryzae immobilized in celite mono- and multi-point were donated by F.Valero (ENZNUT-BIOCATEM network). The following enzymes are from Sigma-Aldrich: Lipozyme ${ }^{\circledR}$ from Mucor miehei, lipase from porcine pancreas type II (lyophilized), Amano lipase PS from Burkholderia cepacia, Palatase ${ }^{\circledR}$ lipase from Rhizomucor miehei, and protease from Bacillus licheniformis.

Lactulose $\geq 95 \%$, vinyl laurate, and 2-methyl-2-butanol (2M2B) were obtained from Sigma-Aldrich (St. Louis, MO, USA). Solvents such as dimethylformamide (DMF), chloroform, methanol, ethyl acetate, and acetonitrile were purchased from Fermont (Monterrey, México). Flash silica (gel 60, 230-400 mesh) was from Merck (Edo. de México, México). HPLC columns C-8 $250 \times 4.6 \mathrm{~mm}$ Microsorb-MV were from Varian. Chromatographic plates Polygram Sil G/UV254 (0.2 mm) were from Machery-Nagel (Düren, Germany). 


\subsection{Methods}

\subsubsection{Enzymatic Reactions}

Lactulose laurate was synthesized by the transesterification of vinyl laurate $(150 \mathrm{~mm})$ and lactulose $(30 \mathrm{~mm}$ ) in $2 \mathrm{M} 2 \mathrm{~B}$ or tert-butanol with $20 \% \mathrm{DMF}$, with $25 \mathrm{mg} / \mathrm{mL}$ of biocatalysts, in a 5 $\mathrm{mL}$ scale. The reactions were performed at 30 and $60^{\circ} \mathrm{C}$ with orbital shaking $(600 \mathrm{rpm})$. The reactions were followed by TLC and HPLC. Different biocatalysts were used for the reaction screening using $25 \mathrm{mg} / \mathrm{mL}$.

\subsubsection{Products Purification}

The synthesis was scaled up to a volume of $120 \mathrm{~mL}$ and incubated for one hour. Immediately after reaching the maximum yield for monoesters, the reaction was stopped to avoid the occurrence of diesters (determined by TLC and HPLC). Subsequently, the mixture was cooled and filtered. Purification continued in two steps: (i) a solvent extraction/partition using chloroform: hexane: acetonitrile (1:3.5:4.5 v/v), and (ii) flash chromatography on silica flash (Gel 40/140 Mesh) using ethyl acetate and methanol $(9: 1 \mathrm{v} / \mathrm{v})$ as eluent.

\subsubsection{TLC and HPLC Analysis}

Analytical TLC was performed on silica gel plates using chloroform/methanol 4:1 (v/v) as eluent. Spots were revealed with a ceric ammonium sulfate staining solution and heating at $120^{\circ} \mathrm{C}$ for $10 \mathrm{~min}$.

The HPLC analysis was carried out by reverse-phase high-performance liquid chromatography (HPLC) using a Varian Prostar (Agilent, Santa Clara, CA, USA), a Microsorb-MV C18 column $(250 \times 4.6 \mathrm{~mm})$ (Agilent, Santa Clara, CA, USA ), and an evaporative light-scattering detector (PL-ELSD 2100 Ice) (Polymer Laboratories-Agilent, Santa Clara, CA, USA) equilibrated at $60{ }^{\circ} \mathrm{C}$ The mobile phase initiated with acetonitrile:water $40: 60(v / v)$ at $1.2 \mathrm{~mL} / \mathrm{min}$ for $4 \mathrm{~min}$. Then, a gradient to 95\% of acetonitrile was performed in $3 \mathrm{~min}$ and continued to pure acetonitrile for $20 \mathrm{~min}$ more. Acetonitrile was then held as a mobile phase for $7 \mathrm{~min}$. Integration was carried out using the Galaxie software Varian (Agilent, Santa Clara, CA, USA). Calibration analyses were performed using monoesters obtained and purified as described above.

\subsubsection{Products Characterization by FT-IR, $1 \mathrm{H}, 13 \mathrm{C}$, and 2D NMR and MS-ESI}

The FT-IR analysis was measured in a Bruker Tensor 27 FT-IR (Bruker Daltonics, Billerica, MA, USA). The mass spectrometry analysis was done using $1 \mathrm{mg}$ of reaction products dissolved in $1 \mathrm{~mL}$ of methanol and directly injected into a Bruker MicrOTOF-QII system by an electrospray ionization (ESI) interface (Bruker Daltonics, Billerica, MA, USA) for its mass spectrometric (MS) analysis. The conditions of MS analysis in the positive ion mode were as follows: drying gas (nitrogen), flow rate, $8 \mathrm{~L} / \mathrm{min}$; gas temperature, $180^{\circ} \mathrm{C}$; scan range, 50-3000 m/z; end plate off set voltage, $500 \mathrm{~V}$; capillary voltage, $4500 \mathrm{~V}$; nebulizer pressure, 2.5 bar. The accurate mass data of the molecular ions were processed through the software DataAnalysis 4.0 (BrukerDaltonics, Billerica, MA, USA), which provided a list of possible elemental formulas using Generate Molecular Formula Editor, as well as a sophisticated comparison of the theoretical with the measured isotope pattern ( $\sigma$ value) for increased confidence in the suggested molecular formula (Bruker Daltonics Technical Note 008, 2004). The widely accepted accuracy threshold for confirmation of elemental compositions was established at $5 \mathrm{ppm}$. The instrument calibration was performed using a 74,900-00-05 Cole Palmer syringe pump (Cole Palmer, Vernon Hills, IL, USA) directly connected to the interface, with a sodium formate cluster solution.

The monoesters obtained from the lipase-catalyzed reactions were characterized by ${ }^{1} \mathrm{H}$ - and ${ }^{13}$ C-NMR (AVANCE III, Bruker NMR System, $750 \mathrm{MHz}$ ) (BrukerDaltonics, Billerica, MA, USA). The NMR spectra were recorded in deuterated methanol $\left(\mathrm{CH}_{3} \mathrm{OD}\right)$. Chemical shifts ( $\delta$ values) were 
given in ppm. ACD/CNMR Predictor 2015 (ACD-Labs, Toronto, Canada) was used to calculate the chemical shifts of the monoesters, using $\mathrm{CH}_{3} \mathrm{OD}$ as a solvent and $187.5 \mathrm{MHz}$ as a theoretical frequency.

\subsubsection{Calculation of HLB Values}

The term HLB (hydrophilic-lipophilic balance) is a systematic scheme of emulsifiers suitable for any application. It is determined by two formulas. In the Griffin method, the HLB value of a nonionic surfactant is proportional to the weight of the fraction of the hydrophilic part: [47-49].

$$
H L B=20 \frac{M_{h}}{M_{T}}
$$

where:

$M_{h}=$ weight fraction of the hydrophilic group

$M_{T}=$ the molecular weight of the whole molecule

The Davies method consists in the assumption that hydrophilic groups have a positive contribution to HLB number, while the hydrophobic groups have a negative effect. Davies calculated these contributions and named them as HLB group numbers.

Knowing the molecular structure, these values are added according to the following formula [50]:

$$
H L B=\sum \text { number of hydrophilic group }+ \text { number of lipophilic group }+7 .
$$

\section{Conclusion}

In this work, we used lactulose for the synthesis of sugar esters. Under the studied conditions, using 2M-2B with DMF (20\%), Novozym 435 preferably synthesized 1-O-lactulose monoester, whereas Lipozyme TL IM showed preferred regioselectivity for 6'-O-lactulose monoester. The products reached conversions over $60 \%$ (1:5, sugar:acyl donor) in less than $2 \mathrm{~h}$. The conversions with lactulose were higher than with other disaccharides, like sucrose, as shown in previous reports. In this research, by using a prebiotic sugar, we demonstrated that it is possible to control the esterification degree in sugar ester synthesis through the modulation of the solvent composition and the biocatalyst, in order to obtain products with new potential properties, like prebiotic surfactants of interest in the food industry.

Supplementary Materials: The following are available online at www.mdpi.com/2073-4344/7/9/263/s1, Figure S1: ${ }^{1} \mathrm{H}$ NMR spectra of purified reaction products: (a) Monoester fraction 1 of Novozym 435 and (b) Monoester fraction 2 of Lipozyme TL IM, Figure S2: ${ }^{13}$ C NMR spectra of purified reaction products: (a) Monoester fraction 1 of Novozym 435 and (b) Monoester fraction 2 of Lipozyme TL IM, Figure S3: HMBC spectra of purified reaction products: (a) Monoester fraction 1 of Novozym 435 and (b) Monoester fraction 2 of Lipozyme TL IM. X axis: ${ }^{1} \mathrm{H}$; Y axis: C., Figure S4: $1 \mathrm{H}$ NMR spectra and integration of monoesters obtained from Novozym 435 , Figure S5: 1H NMR spectra and integration of monoesters obtained from Lipozyme TL IM.

Acknowledgments: This work has been supported by project CB-2015-258385 of the Consejo Nacional de Ciencia y Tecnología (CONACyT). L.F.C.F expresses gratitude for the PhD scholarship 372441 to CONACyT. We thank Dilyn Myers (Fulbright U.S. Program at UAM Cuajimalpa, 2016) for reviewing English text.

Author Contributions: D.R.-D. conceived the concept. L.F.C.-F. and D.R.-D. designed and performed the experiments. D.A.-B. and H.I.B. contributed to the spectroscopic analysis. All of the authors contributed to analyzing the data and writing the manuscript. All of the authors have read and approved the final manuscript.

Conflicts of Interest: The authors declare no conflict of interest. 


\section{References}

1. Ballesteros, A.; Plou, F.J.; Alcalde, M.; Ferrer, M.; García-Arellano, H.; Reyes-Duarte, D.; Ghazi, I. Enzymatic synthesis of sugar esters and oligosaccharides from renewable resources. In Biocatalysis in the Pharmaceutical and Biotechnology Industries; CRC Press: Boca Raton, FL, USA, 2006.

2. Mitsubishi-Kagaku-Foods Corporation. Ryoto sugar esters technical information. 2004. Available online: http:/ / www.mfc.co.jp/english/infor.htm (accessed on 3 September 2017).

3. Abdulmalek, E.; Mohd Saupi, H.S.; Tejo, B.A.; Basri, M.; Salleh, A.B.; Raja Abd Rahman, R.N.Z.; Abdul Rahman, M.B. Improved enzymatic galactose oleate ester synthesis in ionic liquids. J. Mol. Catal. B Enzym. 2012, 76, 37-43. [CrossRef]

4. Nobmann, P.; Smith, A.; Dunne, J.; Henehan, G.; Bourke, P. The antimicrobial efficacy and structure activity relationship of novel carbohydrate fatty acid derivatives against Listeria spp. and food spoilage microorganisms. Int. J. Food Microbiol. 2009, 128, 440-445. [CrossRef] [PubMed]

5. Zhao, L.; Zhang, H.; Hao, T.; Li, S. In vitro antibacterial activities and mechanism of sugar fatty acid esters against five food-related bacteria. Food Chem. 2015, 187, 370-377. [CrossRef] [PubMed]

6. Habulin, M.; Šabeder, S.; Knez, Ž. Enzymatic synthesis of sugar fatty acid esters in organic solvent and in supercritical carbon dioxide and their antimicrobial activity. J. Supercrit. Fluids 2008, 45, 338-345. [CrossRef]

7. Devulapalle, K.S.; Gómez de Segura, A.; Ferrer, M.; Alcalde, M.; Mooser, G.; Plou, F.J. Effect of carbohydrate fatty acid esters on Streptococcus sobrinus and glucosyltransferase activity. Carbohydr. Res. 2004, 339, 1029-1034. [CrossRef] [PubMed]

8. Karlová, T.; Polakova, L.; Šmidrkal, J.; Filip, V. Antimicrobial effects of fatty acid fructose esters. Czech J. Food Sci. 2010, 28, 146-149.

9. Ferrer, M.; Soliveri, J.; Plou, F.J.; López-Cortés, N.; Reyes-Duarte, D.; Christensen, M.; Copa-Patiño, J.L.; Ballesteros, A. Synthesis of sugar esters in solvent mixtures by lipases from Thermomyces lanuginosus and Candida antarctica B, and their antimicrobial properties. Enzym. Microb. Technol. 2005, 36, 391-398. [CrossRef]

10. Puterka, G.J.; Farone, W.; Palmer, T.; Barrington, A. Structure-function relationships affecting the insecticidal and miticidal activity of sugar esters. J. Econ. Entomol. 2003, 96, 636-644. [CrossRef] [PubMed]

11. Noker, P.E.; Lin, T.H.; Hill, D.L.; Shigeoka, T. Metabolism of 14c-labelled sucrose esters of stearic acid in rats. Food Chem. Toxicol. 1997, 35, 589-595. [CrossRef]

12. Shigeoka, T.; Izawa, O.; Kitazawa, K.; Yamauchi, F.; Murata, T. Studies on the metabolic fate of sucrose esters in rats. Food Chem. Toxicol. 1984, 22, 409-414. [CrossRef]

13. Eldred, J.S. Gras Notification for Sucrose Fatty Acid Esters; Center for Food Safety and Applied Nutrition, Food and Drug Administration: Washington, DC, USA, 2003.

14. Sutili, F.K.; Ruela, H.S.; Leite, S.G.F.; Miranda, L.S.d.M.; Leal, I.C.R.; de Souza, R.O.M.A. Lipase-catalyzed esterification of steric hindered fructose derivative by continuous flow and batch conditions. J. Mol. Catal. B Enzym. 2013, 85-86, 37-42. [CrossRef]

15. Van Kempen, S.E.H.J.; Boeriu, C.G.; Schols, H.A.; de Waard, P.; van der Linden, E.; Sagis, L.M.C. Novel surface-active oligofructose fatty acid mono-esters by enzymatic esterification. Food Chem. 2013, 138, 1884-1891. [CrossRef] [PubMed]

16. Van Kempen, S.E.H.J.; Schols, H.A.; van der Linden, E.; Sagis, L.M.C. Effect of variations in the fatty acid chain on functional properties of oligofructose fatty acid esters. Food Hydrocoll. 2014, 40, 22-29. [CrossRef]

17. Horchani, H.; Aissa, I.; Ouertani, S.; Zarai, Z.; Gargouri, Y.; Sayari, A. Staphylococcal lipases: Biotechnological applications. J. Mol. Catal. B Enzym. 2012, 76, 125-132. [CrossRef]

18. Bernal, C.; Illanes, A.; Wilson, L. Heterofunctional hydrophilic-hydrophobic porous silica as support for multipoint covalent immobilization of lipases: Application to lactulose palmitate synthesis. Langmuir 2014, 30, 3557-3566. [CrossRef] [PubMed]

19. Bernal, C.; Illanes, A.; Wilson, L. Improvement of efficiency in the enzymatic synthesis of lactulose palmitate. J. Agric. Food Chem. 2015, 63, 3716-3724. [CrossRef] [PubMed]

20. Corzo, N.; Alonso, J.L.; Azpiroz, F.; Calvo, M.A.; Cirici, M.; Leis, R.; Lombo, F.; Mateos-Aparicio, I.; Plou, F.J.; Ruas-Madiedo, P.; et al. [prebiotics: Concept, properties and beneficial effects]. Nutr. Hosp. 2015, 31 (Suppl. 1), 99-118. [PubMed]

21. Panesar, P.S.; Kumari, S. Lactulose: Production, purification and potential applications. Biotechnol. Adv. 2011, 29, 940-948. [CrossRef] [PubMed] 
22. Lee, K.P.; Kim, H.K. Antibacterial effect of fructose laurate synthesized by Candida antarctica b lipase-mediated transesterification. J. Microbiol. Biotechnol. 2016, 26, 1579-1585. [CrossRef] [PubMed]

23. Schlotterbeck, A.; Lang, S.; Wray, V.; Wagner, F. Lipase-catalyzed monoacylation of fructose. Biotechnol. Lett. 1993, 15, 61-64. [CrossRef]

24. Scheckermann, C.; Schlotterbeck, A.; Schmidt, M.; Wray, V.; Lang, S. Enzymatic monoacylation of fructose by two procedures. Enzym. Microb. Technol. 1995, 17, 157-162. [CrossRef]

25. Li, L.; Ji, F.; Wang, J.; Jiang, B.; Li, Y.; Bao, Y. Efficient mono-acylation of fructose by lipase-catalyzed esterification in ionic liquid co-solvents. Carbohydr. Res. 2015, 416, 51-58. [CrossRef] [PubMed]

26. Li, L.; Ji, F.; Wang, J.; Li, Y.; Bao, Y. Esterification degree of fructose laurate exerted by Candida antarctica lipase b in organic solvents. Enzym. Microb. Technol. 2015, 69, 46-53. [CrossRef] [PubMed]

27. Tükel, S.; Sahin, P.B.; Yildirim, D. Optimization of lipase-catalyzed synthesis of fructose stearate using response surface methodology. Artif. Cells Nanomedicine Biotechnol. 2013, 41, 344-351. [CrossRef] [PubMed]

28. Chen, J.; Kimura, Y.; Adachi, S. Continuous synthesis of 6-O-linoleoyl hexose using a packed-bed reactor system with immobilized lipase. Biochem. Eng. J. 2005, 22, 145-149. [CrossRef]

29. Kitagawa, M.; Fan, H.; Raku, T.; Shibatani, S.; Maekawa, Y.; Hiraguri, Y.; Kurane, R.; Tokiwa, Y. Selective enzymatic preparation of vinyl sugar esters using dmso as a denaturing co-solvent. Biotechnol. Lett. 1999, 21, 355-359. [CrossRef]

30. Riva, S.; Nonini, M.; Ottolina, G.; Danieli, B. Subtilisin-catalyzed esterification of di-and oligosaccharides containing a d-fructose moiety. Carbohydr. Res. 1998, 314, 259-266. [CrossRef]

31. Potier, P.; Bouchu, A.; Gagnaire, J.; Queneau, Y. Proteinase N-catalysed regioselective esterification of sucrose and other mono- and disaccharides. Tetrahedron Asymmetry 2001, 12, 2409-2419. [CrossRef]

32. Wang, X.; Miao, S.; Wang, P.; Zhang, S. Highly efficient synthesis of sucrose monolaurate by alkaline protease protex 61. Bioresour. Technol. 2012, 109, 7-12. [CrossRef] [PubMed]

33. Woudenberg-van Oosterom, M.; van Rantwijk, F.; Sheldon, R.A. Regioselective acylation of disaccharides in tert-butyl alcohol catalyzed by Candida antarctica lipase. Biotechnol. Bioeng. 1996, 49, 328-333. [CrossRef]

34. Walsh, M.K.; Bombyk, R.A.; Wagh, A.; Bingham, A.; Berreau, L.M. Synthesis of lactose monolaurate as influenced by various lipases and solvents. J. Mol. Catal. B Enzym. 2009, 60, 171-177. [CrossRef]

35. Chen, Y.; Nummer, B.; Walsh, M.K. Antilisterial activity of lactose monolaurate in milk, drinkable yogurt and cottage cheese. Lett. Appl. Microbiol. 2014, 58, 156-162. [CrossRef] [PubMed]

36. Kim, J.E.; Han, J.J.; Yoon, J.H.; Rhee, J.S. Effect of salt hydrate pair on lipase-catalyzed regioselective monoacylation of sucrose. Biotechnol. Bioeng. 1998, 57, 121-125. [CrossRef]

37. Ferrer, M.; Cruces, M.A.; Bernabe, M.; Ballesteros, A.; Plou, F.J. Lipase-catalyzed regioselective acylation of sucrose in two-solvent mixtures. Biotechnol. Bioeng. 1999, 65, 10-16. [CrossRef]

38. Casas-Godoy, L.; Duquesne, S.; Bordes, F.; Sandoval, G.; Marty, A. Lipases: An overview. In Lipases and Phospholipases: Methods and Protocols; Sandoval, G., Ed.; Humana Press: Totowa, NJ, USA, 2012; pp. 3-30.

39. Pleiss, J.; Fischer, M.; Schmid, R.D. Anatomy of lipase binding sites: The scissile fatty acid binding site. Chem. Phys. Lipids 1998, 93, 67-80. [CrossRef]

40. Reyes-Duarte, D.; López-Cortés, N.; Ferrer, M.; Plou, F.J.; Ballesteros, A. Parameters affecting productivity in the lipase-catalysed synthesis of sucrose palmitate. Biocatal. Biotransformation 2005, 23. [CrossRef]

41. Neta, N.S.; Teixeira, J.A.; Rodrigues, L.R. Sugar ester surfactants: Enzymatic synthesis and applications in food industry. Crit. Rev. Food Sci. Nutr. 2015, 55, 595-610. [CrossRef] [PubMed]

42. Gumel, A.M.; Annuar, M.S.M.; Heidelberg, T.; Chisti, Y. Lipase mediated synthesis of sugar fatty acid esters. Process Biochem. 2011, 46, 2079-2090. [CrossRef]

43. ICI Americas. The Hlb System: A Time-saving Guide to Emulsifier Selection; ICI Americas, Incorporated: New Castle, DE, USA, 1984; 19p.

44. Hydrophile-lipophile balance of surfactants. Stud. Interface Sci. 2000, 9, 146-266. Available online: http: / / dx.doi.org/10.1016/S1383-7303(00)80016-2 (accessed on 3 September 2017).

45. Zheng, Y.; Zheng, M.; Ma, Z.; Xin, B.; Guo, R.; Xu, X. Sugar fatty acid esters. In Polar Lipids; Elsevier: Amsterdam, The Netherlands, 2015; pp. 215-243.

46. Naik, S.; Basu, A.; Saikia, R.; Madan, B.; Paul, P.; Chaterjee, R.; Brask, J.; Svendsen, A. Lipases for use in industrial biocatalysis: Specificity of selected structural groups of lipases. J. Mol. Catal. B Enzym. 2010, 65, 18-23. [CrossRef] 
47. Gennaro, A.R. Remington Farmacia; Editorial Médica Panamericana: Mexico City, Mexico, 2003; Volume 2, p. 2506.

48. Griffin, W.C. Calculation of HLB values of non-ionic surfactants. Am. Perfum. Essent Oil Rev. 1954, 65, $26-29$.

49. Griffin, W.C. Classification of surface-active agents by "HLB". J. Soc. Cosmet. Chem. 1949, 1, 311-326.

50. Davies, J. A quantitative kinetic theory of emulsion type, i. Physical chemistry of the emulsifying agent, Gas/Liquid and Liquid/Liquid Interface. In Proceedings of the International Congress of Surface Activity, London, UK, 1957; pp. 426-438.

(C) 2017 by the authors. Licensee MDPI, Basel, Switzerland. This article is an open access article distributed under the terms and conditions of the Creative Commons Attribution (CC BY) license (http://creativecommons.org/licenses/by/4.0/). 